\title{
Experiência de um médico pediatra no combate à COVID-19: narrativa autobiográfica
}

\author{
Experience of a pediatrician in combating COVID-19: an autobiographical narrative \\ Experiencia de un pediatra en la lucha contra el COVID-19: una narrativa autobiográfica
}

Recebido: 07/11/2021 | Revisado: 16/11/2021 | Aceito: 22/11/2021 | Publicado: 04/12/2021

Mônica Ramos Daltro

ORCID: https://orcid.org/ 0000-0002-5579-0914 Escola Bahiana de Medicina e Saúde Pública, Brasil E-mail: monicadaltro@bahiana.edu.br

Pedro Guerra Júnior

ORCID: https://orcid.org/0000-0002-9926-1491 Escola Bahiana de Medicina e Saúde Pública, Brasil E-mail: pedrojunior.pos@bahiana.edu.br

Patricia Cerqueira Lima Alves

ORCID: https://orcid.org/0000-0002-1597-6458 Escola Bahiana de Medicina e Saúde Pública, Brasil E-mail: patriciaclsped@gmail.com

\begin{abstract}
Resumo
Um novo vírus altamente contagioso surgiu em dezembro de 2019 na China e rapidamente os casos começaram a se espalhar pelo mundo levando medo a todas as nações. A doença denominada "coronavirus disease 2019" (COVID-19) tornou-se o mais grave problema de saúde pública desta geração. Na faixa etária pediátrica, as manifestações clínicas da COVID-19 podem envolver quaisquer aparelhos e sistemas, desde quadros assintomáticos até óbitos. O objetivo deste estudo foi descrever a experiência de um médico pediatra na assistência à saúde da criança durante o enfrentamento da pandemia da COVID-19. Trata-se de um relato de experiência acerca da sua vivência durante a pandemia construído através das narrativas do próprio autor a partir de suas memórias, desde os primeiros casos até a chegada do vírus ao seu dia a dia. Um dos principais problemas enfrentados foi a escassez de equipamentos de proteção individual. Medidas de proteção adequadas para todos os profissionais, além do suporte psicológico devem ser implementadas nos serviços de saúde, a fim de minimizar a sobrecarga emocional.
\end{abstract}

Palavras-chave: COVID-19; Pandemias; Pediatria.

\begin{abstract}
A new highly contagious virus emerged in December 2019 in China and cases quickly began to spread around the world, causing fear in all nations. The disease called "coronavirus disease 2019" (COVID-19) has become the most serious public health problem of this generation. In the pediatric age group, the clinical manifestations of COVID-19 can involve any device and system, from asymptomatic conditions to death. The aim of this study was to describe the experience of a pediatrician in child health care while facing the COVID-19 pandemic. This is an experience report about his experience during the pandemic, built through the author's own narratives based on his memories, from the first cases to the arrival of the virus in his daily life. One of the main problems faced was the lack of personal protective equipment. Appropriate protective measures for all professionals, in addition to psychological support, must be implemented in health services, in order to minimize the emotional burden.
\end{abstract}

Keywords: COVID-19; Pandemics; Pediatrics.

\section{Resumen}

Un nuevo virus altamente contagioso surgió en diciembre de 2019 en China y los casos comenzaron a extenderse rápidamente por todo el mundo, causando temor en todas las naciones. La enfermedad denominada "enfermedad por coronavirus 2019” (COVID-19) se ha convertido en el problema de salud pública más grave de esta generación. En el grupo de edad pediátrica, las manifestaciones clínicas de COVID-19 pueden involucrar cualquier dispositivo y sistema, desde condiciones asintomáticas hasta la muerte. El objetivo de este estudio fue describir la experiencia de un pediatra en el cuidado de la salud infantil frente a la pandemia de COVID-19. Se trata de un relato vivencial sobre su vivencia durante la pandemia, construido a partir de las propias narrativas del autor a partir de sus recuerdos, desde los primeros casos hasta la llegada del virus a su vida diaria. Uno de los principales problemas enfrentados fue la falta de equipo de protección personal. Se deben implementar medidas de protección adecuadas para todos los profesionales, además del apoyo psicológico, en los servicios de salud, con el fin de minimizar la carga emocional.

Palabras clave: COVID-19; Pandemias; Pediatría. 


\section{Introdução}

Em dezembro de 2019 surgiu em Wuhan, China, um novo vírus altamente contagioso denominado SARS-CoV-2 (Severe Acute Respiratory Syndrome Coronavirus-2). Os casos começaram a se espalhar rapidamente, inicialmente no continente asiático, seguido das demais localidades do mundo, trazendo medo a todas as nações. A doença associada ao SARS-CoV-2, a chamada COVID-19 (coronavirus disease 2019), tornou-se o mais grave problema de saúde pública desta geração (Castagnoli, et al., 2020).

Além de altamente patogênico, o vírus pode evoluir, em alguns casos, rapidamente a óbito (Guimarães, et al., 2020). A transmissão ocorre através do contato direto com gotículas de saliva ou aerossóis produzidos pela fala, tosse e espirros de um indivíduo contaminado, assim como ao tocar o rosto após o contato com superfícies contaminadas (Franco, Franco, Carvalho, Ramos, \& Dias, 2020).

Os casos vão desde assintomáticos, sintomas imperceptíveis ou brandos como febre e tosse, até sintomas graves como dificuldade para respirar, pneumonia e insuficiência respiratória, podendo chegar ao óbito (Tuñas, Silva, Santiago, Maia, \& Silva-Júnior, 2020). Os pacientes idosos e portadores de comorbidades como hipertensão, diabetes, doenças respiratórias crônicas e pessoas imunocomprometidas são mais predispostas a uma maior gravidade da doença (Carvalho, et al., 2020).

Diante deste cenário mundial, para reduzir a propagação do coronavírus, vários países orientavam condutas de isolamento social (Usher, Bhullar, \& Jackson, 2020). Além de afetar todos, o coronavírus não distingue classe econômica, fronteiras, idiomas e ideologias (Daltro \& Segundo, 2020).

A nova realidade fazia parte agora do cotidiano dos profissionais de saúde que se colocavam na linha de frente arriscando suas vidas e vivenciando situações adversas como os desgastes físicos devido às altas cargas de trabalho, problemas psicológicos em decorrência do medo e tensão de se contaminar, como também com a realidade de lidar com a perda de paciente e de colegas de profissão (The Lancet, 2020).

Na pediatria, as manifestações clínicas da COVID-19 podem envolver quaisquer aparelhos e sistemas, variando desde quadros assintomáticos até óbitos. Os sintomas respiratórios são os mais frequentemente relatados. No entanto, sintomas gastrointestinais, manifestações neurológicas e/ou psiquiátricas diversas, manifestações cutâneas, acometimento cardiovascular, quadros hematológicos e síndromes inflamatórias também são descritos (Dong, et al., 2020).

Cerca de um mês após o pico da pandemia, em alguns países da Europa, pesquisadores começaram a descrever um aumento do número de casos da Doença de Kawasaki e de crianças e adolescentes com apresentação semelhante a síndrome do choque tóxico. Logo, a circulação do SARS-CoV-2 e essas manifestações no público infantil foram associadas e começaram a ser estudadas como uma entidade distinta: uma síndrome pós-infecciosa relacionada a desregulação do sistema imune (Viner \& Whittaker, 2020).

As consequências da pandemia da COVID-19 para a saúde de crianças e adolescentes no Brasil tem potencial muito mais negativo comparado aos países da Europa e América do Norte. Vários fatores devem ser considerados e enfrentados, dentre eles, o contingente populacional infantil no país, o número de crianças com problemas crônicos de saúde, os desafios no acesso e qualidade do cuidado, levando à desativação de leitos pediátricos e à crescente vulnerabilidade social (Fiocruz, 2020).

Considerando o cenário da pandemia e o contexto de adaptação para o enfrentamento pelas equipes de saúde em relação ao novo Coronavírus, este estudo tem por objetivo descrever a experiência de um médico pediatra na assistência à saúde da criança durante o enfrentamento da pandemia da COVID-19.

\section{Metodologia}

Trata-se de um relato de experiência acerca da vivência de um pediatra durante a pandemia da COVID-19 construído através das narrativas do próprio autor a partir de suas memórias. O Relato de Experiência é uma narrativa científica de cultivo 
de conhecimento no território da pesquisa qualitativa, cuja construção tem caráter de síntese provisória, aberta à análise do leitor. Seu desenho simultaneamente circunscreve uma experiência, um lugar de fala e um tempo histórico, de forma que esses elementos, articulados a um arcabouço teórico, legitimam a experiência enquanto fenômeno científico a ser comunicado (Daltro \& Faria, 2019).

As ações de enfrentamento da pandemia foram vivenciadas e descritas neste relato no período de janeiro a dezembro de 2020 no setor da pediatria de dois hospitais, um público e um privado, localizados no interior e na capital do estado de Sergipe, respectivamente. O presente estudo respeitou os princípios éticos da Declaração de Helsinque. Tendo em vista que se trata de um estudo autoetnográfico, sem a identificação de sujeitos, o presente relato dispensou a submissão ao Comitê de Ética e Pesquisa e a necessidade da aplicação de Termo de Consentimento Livre e Esclarecido.

\section{Resultados e Discussão}

À medida que o coronavírus avançava na China causando um número de mortes cada vez maior, o mundo começava timidamente a ficar atento a essa nova doença. Naquele momento, o vírus foi subestimado por médicos e pessoas influentes no país. Observava-se que a China construía um hospital de campanha em apenas dez dias para combater o coronavírus e, devido à impressão de tamanha rapidez e eficiência, havia o questionamento se era possível repetir o mesmo no Brasil. No entanto, nesse momento, o país estava as vésperas da maior festa popular e o foco estava voltado para o carnaval. Assim, ao invés de as primeiras medidas de combate serem tomadas, as pessoas se aglomeravam nas ruas. Não havia noção do que estava por vir.

$\mathrm{O}$ tempo passou e o foco agora era a Itália. O vírus tinha ultrapassado fronteiras continentais. A Europa apresentou o lookdown, cenas de como a vida era a partir daquele momento inundavam os noticiários: filas nos estacionamentos dos supermercados aguardando sua vez para compras de mantimentos, cantorias nas sacadas para diminuir o impacto do isolamento social. Logo a seguir, era a vez da América. Nova York agonizava com hospitais lotados, além da falta de ventilador mecânico e profissionais de saúde esgotados com o trabalho estressante. Nesse momento, não havia mais dúvida: era questão de tempo da chegada do vírus ao país.

O primeiro momento de sensibilidade pessoal ocorreu ao presenciar uma fila de caminhões transportando caixões com vítimas do coronavírus. Com expectativa de vida alta na região norte da Itália e um número de idosos significativo, a doença não perdoou. Os hospitais não estavam dando conta de tanta gente necessitando de respirador mecânico. Mortes começavam a acontecer não só pela agressividade do vírus, mas também pela falta de recursos médico-hospitalares. Médicos tinham que decidir quem vivia e quem morria. As mortes na Espanha, na França, no mundo só aumentavam.

A palavra empatia, do grego empatheia, significa reconhecer o sentimento do outro e refere-se a uma resposta cognitiva e emocional a uma experiência vivida por uma outra pessoa (Davis, 1983). Começou, portanto, a reflexão nesse cenário pandêmico, como a atitude empática, construída ao longo de uma formação profissional, ultrapassando a relação médicopaciente.

Começam a sair as primeiras publicações em revistas cientificamente respeitadas, muitas delas recheadas de críticas pelos múltiplos vieses em seus estudos. No Brasil, saem os primeiros protocolos das renomadas instituições sugerindo como se deveria conduzir a doença. As orientações gerais indicavam a importância das redes de cuidado e dos padrões urbanos para ampliar ou conter as escaladas de disseminação do vírus (Jardim \& Buckeridge, 2020).

Em meados de março, como testemunho pessoal, foram vistas as primeiras iniciativas na direção de estabelecer medidas restritivas para o isolamento domiciliar: fechamento de escolas, comércio, entretenimento. Somente serviços essenciais a partir deste momento deveriam funcionar. Os hospitais também iniciavam um plano de isolar leitos dedicados para suspeitos e confirmados com COVID-19. 
Como em vários locais do planeta, a escassez de equipamentos de proteção individual (EPI) se tornou um dos principais problemas enfrentados entre os profissionais de saúde do Brasil. Seguindo padrões internacionais, iniciou-se a procura do principal equipamento de proteção individual: a máscara. Para os profissionais de saúde, a máscara recomendada N95 tornou-se um objeto precioso e não era encontrada nem para aquisição privada nas lojas. Essa necessidade de garantir a prevenção do contágio dos trabalhadores e condições adequadas de trabalho estava colocada como elemento central para viabilizar uma atuação profissional psiquicamente estável e motivada, dada a gravidade do contexto (Huh, 2020).

Sentimentos de angústia e ansiedade, além de traumatização tanto direta (dermatites, reações alérgicas pelo uso do álcool gel, suor excessivo devido ao uso prolongado de roupas, lesões na face pelo uso constante de máscaras), quanto indireta entre os profissionais de saúde, devido às altas cargas de trabalho e ausência de equipamentos de proteção foram alguns dos primeiros resultados encontrados nesses meses de pandemia (Li, et al., 2020). Com relação ao EPI, dois problemas se destacaram: a escassez e o uso inadequado (Cook, 2020). Eram disponibilizadas máscaras cirúrgicas por longas horas sem a devida troca necessária. Diariamente novas regras eram determinadas, adaptadas à condição do estoque do momento.

A experiência profissional embora empática, passa a ser atravessada pelo medo. Medo de ir trabalhar, medo de contaminar a família, medo de perder os colegas mais ou menos vulneráveis. Cada vez que chegava ao trabalho e, ao se deparar com a obrigação de usar um equipamento inadequado, emergia a possibilidade de desistir, de ir para casa e abandonar a luta. Com medo e correndo alto risco de contaminação, as primeiras semanas dessa batalha foram enfrentadas.

Além de trabalhar em situações inseguras, os profissionais sentiam-se angustiados pela incerteza do tratamento clínico, além da falta de precisão das informações sobre a evolução da pandemia (Smith, Fowie, \& Li, 2020). Muitos profissionais afirmavam que a maior preocupação era levar a infecção para suas famílias. Relataram também que a não colaboração dos pacientes estava lhes causando sofrimentos psicológicos, pois muitos não respeitavam as medidas preventivas, consequentemente, aumentando as chances de superlotação das unidades hospitalares. As equipes informaram suas preocupações em relação à disponibilidade de equipamentos de proteção e a sensação de impotência frente aos pacientes graves.

A maioria dos profissionais de saúde não possuíam treinamento adequado para combater a doença, representando uma das principais aflições observadas na equipe de pediatras. Era um cenário de incertezas, com a presente ameaça de colapso do sistema de saúde, falta de uma coordenação nacional de cuidados em saúde, uma profunda desigualdade territorial, de renda, de condições de vida e de proteção social. Doação de uma loja de material médico-hospitalar que disponibilizou todo o estoque de máscaras N95 foi possível em um dos referidos hospitais. Essa perspectiva coloca em evidência a importância da articulação da sociedade civil para promover ação coletiva de luta contra um inimigo comum, se deslocando das lógicas binárias e de polarização que vem estruturando nossa cultura (Andion, 2020).

Foram inauguradas áreas dedicadas à pacientes suspeitos e confirmados com COVID-19 que foram aos poucos sendo ocupadas. Pela primeira vez, foi possível a aproximação com um paciente com COVID-19: o vírus tinha chegado finalmente até o local. Pouco tempo depois, foi realizada uma intubação da primeira criança suspeita com quadro respiratório grave que logo após foi confirmado o vírus da COVID-19: estava ali a primeira criança grave do Estado de Sergipe. Agora sim, havia o contato direto com o vírus, além da realização de um procedimento potencialmente contaminante. Logo, surgiram os primeiros sintomas: cefaleia, dores no corpo e febre. Medo, desespero, tensão, angústia permearam o psicológico até realizar o exame e sair o resultado.

Ao se deslocar para o local de realização do teste RT-PCR, reflexões surgiam sobre ser o último momento, a última vez. Pensamentos sobre o "vidro fosco" nos pulmões e indicação de internamento. Pensamentos sobre a dessaturação e indicação de intubação e ventilação mecânica. Pensamentos sobre o fim. $24 \mathrm{~h}$ de espera até o resultado que negativo: alívio imenso. Esse conjunto de experiência colocou em circulação a reflexão sobre os processos de cuidado pessoal, antes automatizados. A partir 
dessa data, foi adotada a conduta de não tocar mais nos olhos, boca e nariz, em hipótese alguma, e de usar em 100\% do tempo durante a estada em ambiente hospitalar a máscara N95 e todos os demais itens recomendados.

Foucault (2004), filósofo francês contemporâneo, se inspirou nos gregos para problematizar a noção de ética. Para estes, a experiência de cuidado de si se estabelece a partir das liberdades individual e cívica que tem o cuidar de si como preocupação essencial. Contudo, cuidar de si, se coloca como uma atitude crítica de reinvenção de si mesmo nas relações, envolve o conhecimento sobre si mesmo, seus limites e possibilidades que garanta a liberdade e o cuidado do outro. Na experiência da pandemia, o medo me trouxe a necessidade de cuidado e isso estava constituído como uma atitude ética e não como uma fragilidade psíquica, mas como força.

Cada criança que chegava à urgência era prontamente classificada em respiratória ou não. Ao entrar na área dedicada, o semblante da mãe e responsável era o de tensão, o de medo. As dúvidas sobre a nova doença, as novas condutas apresentadas, o isolamento dos outros pacientes e do mundo eram a todo momento indagados. A equipe de saúde também preocupada, afetada empática e eticamente, reagia com a dúvida e a incerteza se aquele tratamento iria ser efetivo ou não.

$\mathrm{O}$ assistir aos pequenos pacientes, que na maioria das vezes não tinham ciência do que estava se passando naquele momento delicado da humanidade, foi uma experiência difícil e desafiadora. A paramentação obrigatória do profissional assustava a criança. $\mathrm{O}$ contexto lúdico do atendimento pediátrico era trocado por um cenário frio e assustador. Era evidente que a relação médico-paciente estava cada vez mais distante, o medo fazia com que a consulta se tornasse menos humanizada. $\mathrm{O}$ sentimento de culpa também era visível nos rostos dos pais, visto que em muitas ocasiões eles próprios eram os responsáveis pela transmissão do vírus.

Os dias foram passando e começaram as mortes vítimas da COVID-19 no Estado de Sergipe, nos hospitais deste relato, as mortes de colegas médicos. Muitos próximos chegaram a situações bem críticas, muitos dias intubados, drogas vasoativas, muitos ficaram entre a vida e a morte. Muita espera pelo chamado "pico da doença", que só chegou cinco meses após o primeiro caso. 150 dias incansáveis de luta até perceber que a curva estava caindo. 150 dias onde era presenciado colegas positivando duas vezes, colegas afastados por 14 dias de seus empregos para cumprir o isolamento domiciliar.

Curiosamente, aos poucos a vida vai tentando voltar ao normal, ou melhor, adaptar-se a um normal que demanda resiliência, resistência, ética e cuidado de si. Planos de retomada gradativa em todos os locais foram implantados. Aos poucos a rigidez na nossa mente vai se liberando e a tensão vai diminuindo.

O cuidado dos pediatras entre si foi essencial para a execução de ações nas unidades com empatia e controle emocional diante do pânico causado pela pandemia. Um cuidado que implicava a necessidade de uma equipe de trabalho bem informada, apta a desenvolver ações psicoeducativas, pois além do vírus, tem sido necessário combater a desinformação, as fake news e, por vezes, investir numa mudança de crença pessoal. Além das crianças em processo de adoecimento, as mães e cuidadores, imersos nesse universo de incerteza demandaram da pediatria ações de escuta, acolhimento e oferecimento de instruções na busca do cuidado ético.

Ficou evidente o protagonismo não só do médico, mas também de todos os profissionais de saúde, sendo indispensável para o funcionamento do conjunto de ações. Ressalta-se a habilidade técnica assistencial e científica desses profissionais, assim como sua sensibilidade de cuidar e ser cuidado, de gerenciar e empoderar toda a equipe. Nesse clima de tensão causado pela pandemia, foi possível estabelecer um ambiente de trabalho harmonioso, alcançando a ressignificação das relações e dos processos de trabalho.

Reafirmar o papel de cada profissional integrante das equipes de saúde e cuidar dos aspectos relacionados à saúde física e mental desses profissionais são ações de fácil implementação, que contribuíram no enfrentamento da COVID-19. É possível se reinventar mesmo na crise, adaptar-se em situações críticas, superar desafios e garantir atenção à saúde de qualidade à população. Após passarem a experimentar situações adversas em seu ambiente de trabalho e no convívio familiar, o estado 
psicológico dos profissionais de saúde foi afetado significativamente. É possível que a pressão psicológica possa causar maiores danos que o próprio vírus.

\section{Considerações Finais}

A experiência de trabalho como pediatra no contexto da pandemia da COVID-19 demanda uma condução ética e empática que envolve preocupação específica com a saúde mental do médico e da equipe. O contexto esteve marcado pelo risco do vírus, mas também pela desinformação e vulnerabilidade das condições de trabalho que se colocam frente a exposição prolongada às situações de contágio. O conjunto da experiência mostra a importância do trabalho em equipe, mas também um cenário cotidiano de alta pressão psicológica, concordante com os estudos encontrados na literatura.

Diante dessa turbulência emocional vivenciada pelas equipes de pediatras, é necessário oferecer medidas de proteção adequadas para esses profissionais. O suporte psicológico é uma dessas estratégias que deveria ser implantado em todos os serviços de saúde, a fim de minimizar a sobrecarga emocional, visto que a redução da ansiedade ocasionada pelo medo de se contaminar melhora.

A principal contribuição deste estudo foi mostrar que através da prevenção, da elaboração de estratégias, da união da equipe e da ajuda do suporte psicológico podemos sair vitoriosos dessa guerra e deixar um legado para as gerações futuras.

Observa-se limitação quanto à abrangência da experiência aqui narrada, pois apesar de se tratar de um profissional da linha de frente no combate ao novo coronavírus, este relato limita-se às condutas adotadas e percebidas pelo mesmo em seus locais de trabalho, não abrangendo outros profissionais de diferentes áreas nem outras unidades de saúde que podem ter experiências distintas, talvez com maior nível de tensão e desarticulação, impactando de diversas maneiras a efetividade e eficiência das ações. Finalmente, como se trata de uma doença ainda em estudo e com novas descobertas diariamente, as ações aqui narradas apresentam limitações pela própria inexperiência dos profissionais que conduzem os serviços de saúde frente ao manejo da COVID-19. Assim, sugere-se novos estudos sobre o impacto da pandemia na perspectiva dos pediatras das diferentes regiões do país.

\section{Referências}

Andion, C. (2020). Atuação da sociedade civil no enfrentamento dos efeitos da COVID-19 no Brasil. Rev. Adm. Pública, 54 (4), $936-51$.

Carvalho, A. P., et al. (2020). Novo coronavírus (COVID-19). Sociedade Brasileira de Pediatria, Departamento científico de infectologia.

Castagnoli, R., et al. (2020). Severe Acute Respiratory Syndrome Coronavirus 2 (SARS-CoV-2) Infection in Children and Adolescents: A Systematic Review. JAMA Pediatr, 174 (9), 882-889.

Cook, T. M. (2020). Personal protective equipment during the coronavirus disease (COVID) 2019 pandemic - a narrative review. Anaesthesia, 75 (7), $920-7$.

Daltro, M. \& Segundo, J. D. B. (2020). A pandemia que nos mostra quem somos? Revista Psicologia, Diversidade e Saúde, 9 (1), $5-8$.

Daltro, M. R., \& Faria, A. A. (2019). Relato de experiência: Uma narrativa científica na pós-modernidade. Estudos e Pesquisas em Psicologia, 19 (1), $223-237$.

Davis. M. H. (1983). Measuring individual difference in emphaty: Evidence for a multidimensional approach. J Person Soc Phychol., 44, 113-26.

Dong, Y., et al. (2020). Epidemiology of COVID-19 among children in china. Pediatrics, 145 (6), e20200702. Recuperado em doi:10.1542/peds.2020-0702

Fiocruz. Instituto Nacional de Saúde da Mulher, da Criança e do Adolescente Fernandes Figueira. (2020). COVID-19 e Saúde da Criança e do Adolescente. https://portaldeboaspraticas.iff.fiocruz.br/atencaocrianca/covid-19-saude-crianca-e-adolescente

Foucault, M. (2004). Ética, sexualidade e política (Ditos e Escritos, V). Rio de Janeiro: Forense Universitária.

Franco, A. G., Franco, A. B. G., Carvalho, G. A. P., Ramos, E. V., \& Dias, S. C. (2020). Surgical masks in times of coronavirus. InterAmerican Journal of Medicine and Health, 3, e202003003. Recuperado de https://doi.org/10.31005/iajmh.v3i0.73

Guimarães, H. P., et al. (2020). Coronavírus e Medicina de Emergência: Recomendações para o atendimento inicial do Médico Emergencista pela Associação Brasileira de Medicina de Emergência https://www.amib.org.br/fileadmin/user_upload/POSICIONAMENTO_ABRAMEDECORONAVIRUS_-_03-__10032020.pdf 
Research, Society and Development, v. 10, n. 16, e09101622940, 2021

(CC BY 4.0) | ISSN 2525-3409 | DOI: http://dx.doi.org/10.33448/rsd-v10i16.22940

Huh, S. (2020). How to train health personnel to protect themselves from SARS-CoV-2 (novel coronavirus) infection when caring for a patient or suspected case. J Educ Eval Health Prof, 17, 10. https://doi.org/10.3352/jeehp.2020.17.10

Jardim, V. C. \& Buckeridge, M. S. (2020). Análise sistêmica do município de São Paulo e suas implicações para o avanço dos casos de Covid-19. Estudos avançados, 34 (99), 2020.

Li, Z. et al. (2020). Vicarious traumatization in the general public, members, and non-members of medical teams aiding in COVID-19 control. Brain Behav Immun., 88, 916-919.

Smith, G. D., Fowie, N. G., \& Li, W. H. C. (2020). COVID-19: Emerging compassion, courage and resilience in the face of misinformation and adversity. J Clin Nurs., 29, 1425-8.

The Lancet. (2020). COVID-19: protecting health-care workers. https://www.thelancet.com/action/showPdf?pii=S0140-6736\%2820\%2930644-9

Tuñas, I. T. C., Silva, E. T., Santiago, S. B. S., Maia, K. D., \& Silva-Júnior, G. O. (2020). Doença pelo Coronavírus 2019 (COVID-19): Uma abordagem preventiva para Odontologia. Revista Brasileira de Odontologia, 77, e1766. https://revista.aborj.org.br/index.php/rbo/article/view/1776/pdf

Usher, K., Bhullar, N., \& Jackson, D. (2020). Life in the pandemic: Social isolation and mental health. J Clin Nurs., 29 (15-16), 2756-7.

Viner, R. M., \& Whittaker, E. (2020). Kawasaki-like disease: emerging complication during the COVID-19 pandemic. The Lancet, 395 (10239), $1741-1743$. 